\title{
Distribution of Cranberry Fruit-Rotting Fungi in New Jersey and Evidence for Nonspecific Host Resistance
}

\author{
C. M. Stiles and P. V. Oudemans
}

Rutgers University, Blueberry and Cranberry Research and Extension Center, Lake Oswego Road, Chatsworth, NJ 08019. Current address of C. M. Stiles: Department of Biology, Valdosta State University, Valdosta, GA 81698. Accepted for publication 25 November 1998.

\begin{abstract}
Stiles, C. M., and Oudemans, P. V. 1999. Distribution of cranberry fruitrotting fungi in New Jersey and evidence for nonspecific host resistance. Phytopathology 89:218-225.

A survey was conducted over a 3-year period to determine the frequencies and distributions of fruit-rotting fungi in New Jersey cranberry beds. In the first 2 years of the study, Physalospora vaccinii and Glomerella cingulata were the most prevalent and widespread field-rotting fungi. In the third year, the frequency of $G$. cingulata declined markedly. Other species such as Coleophoma empetri, Phyllosticta vaccinii, and Phomopsis

tions. Storage-rotting fungi including Allantophomopsis cytisporea and A. lycopodina were isolated at low frequencies, but were widely distributed within the growing region. On sound fruit, a somewhat different profile emerged. Fungi such as Phyllosticta elongata, Alternaria spp., and Physalospora vaccinii were commonly isolated. In comparisons among different cranberry cultivars, no differences in the fungal profiles were seen. This was interpreted to indicate that if differences in fruit-rot resistance exist, they are likely to be general forms of resistance rather than fungal speciesspecific mechanisms.
\end{abstract} vaccinii were isolated at high frequencies from a limited number of loca-

The domestication and commercial production of the large American cranberry (Vaccinium macrocarpon Aiton) began during the middle of the nineteenth century in Massachusetts and New Jersey (25). During that time, cranberry fruit rot was the leading factor limiting fruit production (9). In a classic work, Shear et al. (16) outlined the causes of cranberry fruit rot and implicated 8 fungal species as having a major impact and another 24 species as having a minor impact. The results presented by Shear et al. (16) were a summary of extensive surveys carried out by cranberry researchers in New Jersey and Massachusetts $(17-20,26)$ and to a lesser extent in Wisconsin, Oregon, and Washington (1). Zuckerman (27) in Massachusetts and Jeffers (10) in Wisconsin expanded upon these earlier surveys.

The current composition of the fruit-rot complex in New Jersey is poorly understood. However, the fungicides currently registered are sufficiently broad spectrum to control fruit rot to an economically acceptable level. If the registration of two fungicides (chlorothalonil and mancozeb) is revoked, fruit rot could increase and dramatically reduce cranberry production in the northeast (12). Surveys of the type described above provide vital data that can be used to design better cranberry fruit-rot control strategies that may ultimately incorporate new fungicide chemistries with narrow spectra of activities. Thus, a current working knowledge of the species composition of cranberry fruit rot could become an essential component for management of this disease complex.

Taxonomic investigations conducted during the past 15 years have resulted in some significant revisions in the classification of the cranberry fruit-rotting fungi. Many of the revisions resulted in splitting taxa $(4,23)$, as well as establishment of a number of new species $(3,5,22)$. One recent publication (6) has incorporated the majority of significant taxonomic changes made for cranberry fruit-rotting fungi.

Cranberry fruit rot can occur in two forms, either as a preharvest field rot or a postharvest storage rot (12). Field rot is of primary

Corresponding author: P. V. Oudemans

E-mail address: oudemans@ @esop.rutgers.edu

Publication no. P-1998-1229-03R

(C) 1999 The American Phytopathological Society
Additional keywords: Vaccinium macrocarpon. concern because the majority of the crop is used for processing and the fruit is generally frozen soon after harvest. Infection may occur during the growing season and the pathogen remains latent until fruit ripening. On the other hand, storage rots affect fruit destined for the fresh market and infections can occur during either the growing season or the harvest process. Fruit harvested from flooded beds (water-harvested) tend to be infected to a higher degree with storage-rotting fungi than fruit harvested from dry beds. Thus, fruit destined for the fresh market is often dry-harvested.

New Jersey is the most southern region in the Northern Hemisphere where cranberries are produced commercially. It is also subject to intense fruit rot pressure, due in part to high summer temperatures (7). There have been no recent surveys aimed at investigating the frequencies of cranberry fruit-rotting fungi in commercial cranberry farms in New Jersey (26). Significant changes in farming techniques such as improved timing of fungicide application and modifications of the rate and frequency of nitrogen fertilizer usage have improved yields (13), but may have also caused changes in the species and frequencies of the fruit-rotting fungi. At this time, no studies have systematically investigated intra-regional variation in the frequencies of fruit-rotting fungi.

In this study, a survey for cranberry fruit-rotting fungi in New Jersey was conducted with two major objectives. The first objective was to determine the frequencies and variation of fungal rot species present across the commercial cranberry-growing region of $\mathrm{New}$ Jersey. This area encompasses approximately 1,418 ha of cultivated commercial beds in Atlantic, Burlington, and Ocean counties in the southern part of the state, as well as an undetermined area including abandoned farms and native stands. The survey for fruit-rot fungi (primarily field-rotting species) was conducted over a 3-year period (1994 to 1996) and encompassed 10 to 40 sampling sites. In addition, several unmanaged, abandoned cranberry beds and one native cranberry stand were sampled to determine if major differences in fungal species existed between these and the commercial beds. A study comparing the fungi present in sound versus rotted fruit was also conducted. The second objective was to determine if the frequencies of the various fruit-rotting fungi were affected by host cultivar to assess the likelihood of fungal species-specific host resistance. 


\section{MATERIALS AND METHODS}

Sampling sites and methodology. Cranberry fruit showing symptoms of fungal rot were sampled from 36 and 40 commercial cranberry beds (Table 1) just prior to harvest in 1994 and 1995, respectively. Commercial beds, in general, received four fungicide applications aimed at fruit-rot control (Table 1). The fungicides (ferbam, mancozeb, or chlorothalonil) were applied at early bloom (5 to 15 June) and at 10- to 14-day intervals thereafter. At each location, 100 symptomatic fruit were collected at approximately 1-m intervals along linear transects through each bed. The number of transects was proportional to the incidence of fruit rot, because a rotted fruit was not necessarily found every meter, and, therefore, ranged from two to four transects per bed. Fruit from each bed was placed in plastic bags and stored at $4^{\circ} \mathrm{C}$ for up to 1 week prior to isolation.

An additional eight sites were sampled in 1995 to estimate the levels of fruit rot in the field and to compare the species of fungi present in sound versus rotted fruit. For this, all fruit were harvested within three arbitrarily selected $0.84-\mathrm{m}^{2}$ quadrats within a bed. Fungi were isolated and identified as described below from 30 sound and 30 rotted berries (if available) from each sample.

In 1996, 11 commercial beds were sampled (Table 1) in a similar manner as described for 1994 to 1995 , with the exception that 100 sound fruit were collected in addition to the 100 rotted fruit. Samples collected in 1996 included beds shown to harbor high frequencies of Glomerella cingulata (Stoneman) Spaulding \& H. Schrenk during the previous 2 years.

Comparison among cultivars. Two studies were conducted to compare the relative numbers of fungal species occurring in rotted fruit of different cultivars. In the first study, 11 locations were selected in which beds with 'Early Black' and 'Stevens' were in close proximity (100 to $300 \mathrm{~m}$ ). Fruit was sampled as before, and 100 rotted fruit per bed were cultured. The second study utilized an experimental cranberry bed measuring $18.3 \times 146.3 \mathrm{~m}$ that was planted in 1985 with 10 cranberry cultivars at the Rutgers University Blueberry and Cranberry Research and Extension Center in Chatsworth, NJ. The planting consisted of four rows (blocks) of 10 cultivar plots measuring $3.0 \times 9.0 \mathrm{~m}$. Cultivar plots were ran-

TABLE 1. Description of commercial cranberry beds in New Jersey from which cranberry fruit was sampled in 1994 to 1996

\begin{tabular}{|c|c|c|c|c|c|c|c|c|c|}
\hline \multirow[b]{2}{*}{ Code } & \multirow[b]{2}{*}{ Location $^{\mathrm{a}}$} & \multirow[b]{2}{*}{ Area (ha) } & \multirow[b]{2}{*}{ Cultivar ${ }^{\mathrm{b}}$} & \multirow[b]{2}{*}{ Planted $^{\mathrm{c}}$} & \multirow[b]{2}{*}{ Sanded $^{\mathrm{d}}$} & \multirow[b]{2}{*}{ Spray schedule } & \multicolumn{3}{|c|}{ Percent fruit damage $\mathrm{f}^{\mathrm{f}}$} \\
\hline & & & & & & & 1994 & 1995 & 1996 \\
\hline 10 & Cassville & 1.0 & EB & na & na & na & $\mathrm{ns}$ & 1.1 & ns \\
\hline 11 & Browns Mills & 1.9 & EB & 1968 & 1991 & FMCC & 1.1 & 2.4 & ns \\
\hline 12 & Browns Mills & 2.6 & ST & 1990 & Never & FMCC & 7.2 & na & ns \\
\hline 14 & Toms River & 12.8 & EB & $<1940$ & Never & $\mathrm{CCCM}$ & ns & 15.3 & ns \\
\hline 15 & Browns Mills & 4.3 & EB & $<1940$ & Never & MCCM & ns & 3.5 & ns \\
\hline 18 & Pemberton & 1.6 & ST & 1991 & Never & MCCC & na & na & ns \\
\hline 19 & Pemberton & 1.8 & EB & 1989 & 1992 & $\mathrm{MCCC}$ & na & na & ns \\
\hline 21 & Indian Mills & 0.7 & ST & 1991 & Never & CMCC & 1.4 & 3.7 & 2.4 \\
\hline 22 & Indian Mills & 0.9 & EB & $<1960$ & 1992 & $\mathrm{CMCC}$ & 2.6 & 9.9 & 6.0 \\
\hline 23 & Indian Mills & 2.1 & EB & $<1900$ & Never & $--\mathrm{CC}$ & 14.0 & 5.8 & ns \\
\hline 24 & Indian Mills & 2.4 & EB & na & na & na & 11.2 & 10.6 & ns \\
\hline 27 & Indian Mills & 3.6 & EB & 1985 & 1991 & CMCC & 1.4 & 1.9 & ns \\
\hline 28 & Indian Mills & 0.5 & ST & 1991 & Never & CMCC & 12.7 & 7.7 & ns \\
\hline 29 & White Horse & 1.6 & EB & na & na & na & 2.9 & 3.0 & ns \\
\hline 30 & White Horse & 1.7 & EB & 1984 & 1991, 1994 & CMCC & 2.6 & 2.6 & ns \\
\hline 31 & White Horse & 1.8 & $\mathrm{ST}$ & 1986 & 1992 & CMCC & 3.6 & 3.0 & $\mathrm{~ns}$ \\
\hline 32 & Chatsworth & 3.5 & EB & $<1960$ & 1991 & MMCC & 1.2 & 1.0 & 2.2 \\
\hline 33 & Chatsworth & 1.6 & $\mathrm{ST}$ & $\sim 1980$ & Never & MMCC & 1.0 & 1.4 & 1.7 \\
\hline 34 & Chatsworth & 2.9 & EB & $<1960$ & Never & MMCC & 3.2 & 1.8 & 2.7 \\
\hline 35 & Chatsworth & 2.1 & $\mathrm{ST}$ & $\sim 1976$ & Never & $\mathrm{MMCC}$ & 4.3 & 3.2 & 4.8 \\
\hline 36 & Chatsworth & 2.2 & EB & $<1960$ & 1989 & MMCC & 9.2 & 3.8 & 4.2 \\
\hline 37 & Chatsworth & 1.9 & ST & 1989 & Never & MMCC & 6.2 & 0.9 & 3.7 \\
\hline 70 & Chatsworth & 2.6 & EB & $<1960$ & 1990 & MMCC & $\mathrm{ns}$ & 5.1 & ns \\
\hline 71 & Chatsworth & 3.8 & EB & $<1960$ & 1991 & MMCC & ns & 3.3 & ns \\
\hline 38 & Speedwell & 2.1 & EB & 1967 & 1987,1993 & CMCC & 1.1 & 1.2 & ns \\
\hline 39 & Speedwell & 1.6 & ST & 1989 & 1994 & CMCC & 2.4 & 4.7 & ns \\
\hline 40 & Speedwell & 2.4 & $\mathrm{BL}$ & 1989 & 1994 & CMCC & 1.4 & 6.5 & ns \\
\hline 41 & Hog Wallow & 1.2 & $\mathrm{ST}$ & 1974 & 1994 & FMCC & 3.3 & 6.2 & 3.9 \\
\hline 42 & Hog Wallow & 1.2 & EB & 1975 & 1994 & FMCC & 1.7 & 2.9 & 1.4 \\
\hline 43 & Hog Wallow & 2.0 & EB & 1948 & 1994 & FMCC & 2.8 & 4.6 & ns \\
\hline 44 & Oswego & 2.6 & EB & 1954 & 1993 & FMCC & 8.4 & 4.9 & ns \\
\hline 72 & Oswego & 1.7 & EB & 1945 & 1993 & FMCC & ns & 1.3 & ns \\
\hline 45 & Hog Wallow & 2.6 & EB & 1940 & 1994 & FMCC & 3.1 & 3.5 & ns \\
\hline 46 & Hog Wallow & 0.8 & ST & 1966 & 1995 & FMCC & 1.6 & 3.3 & ns \\
\hline 47 & Jenkins & 1.3 & EB & $<1960$ & na & FMCC & 0.8 & 1.3 & ns \\
\hline 48 & Jenkins & 1.4 & $\mathrm{~EB}$ & $<1960$ & na & FMCC & 7.3 & 3.9 & ns \\
\hline 49 & Oswego & 0.2 & Various & 1985 & Never & CMCC & 12.0 & 15.3 & ns \\
\hline 50 & Calico Ridge & 1.9 & $\mathrm{~EB}$ & 1962 & $\ldots$ & $-\mathrm{FCC}$ & 4.2 & 3.9 & ns \\
\hline 51 & Calico Ridge & 2.1 & EB & $<1940$ & 1987 & $-\mathrm{FCC}$ & 4.4 & 0.2 & ns \\
\hline 52 & Bulltown & 0.7 & EB & na & na & na & 11.5 & 1.6 & ns \\
\hline 55 & Medford & 1.1 & $\mathrm{~EB}$ & na & na & na & $\sim 25.0^{f}$ & ns & ns \\
\hline 56 & Medford & 1.3 & $\mathrm{HO}$ & na & na & na & $>50.0^{f}$ & ns & ns \\
\hline
\end{tabular}

${ }^{a}$ All locations in Burlington County, NJ, except Toms River, which is located in Ocean County.

${ }^{\mathrm{b}} \mathrm{EB}=$ 'Early Black', $\mathrm{ST}=$ 'Stevens', $\mathrm{BL}=$ 'Ben Lear', and $\mathrm{HO}=$ 'Howes'.

${ }^{c}$ Refers to the year the bed was planted.

${ }^{\mathrm{d}}$ Beds are sanded during the winter months by placing 5 to $10 \mathrm{~cm}$ of washed sand over the vines. Some beds have never been sanded.

${ }^{\mathrm{e}} \mathrm{F}=$ ferbam, $\mathrm{M}=$ mancozeb, and $\mathrm{C}=$ chlorothalonil; fungicides generally are applied beginning at scattered- to mid-bloom and continue on a 7- to 14-day schedule. $* *=$ A delayed first spray; and na $=$ information not available.

f Percent fruit damage estimates determined at receiving station after harvest of each cranberry bed. For sites 11, 12, 22, 47, and 52 in 1994 and sites $11,21,22$, 23, 47, 48, and 52 in 1995, damage estimates were obtained on fruit bulked with adjoining cranberry beds. ns = Bed not sampled during that year. 
domized such that each cultivar occurred within each block. Alleys between the plots were maintained by frequent cultivation to prevent overlapping vine growth between cultivars. All plots received four fungicide applications beginning at early bloom (4 to 5 June) and every 10 to 14 days until post bloom (12 to 16 July). The two fungicides used were mancozeb (3.4 kg a.i. per ha) and chlorothalonil (1.7 kg a.i. per ha). In 1994, chlorothalonil was applied on the first three dates and mancozeb on the final date. In 1995, mancozeb was applied on the first two dates and chlorothalonil on the final two dates. The insecticide azinophos-methyl was applied both prebloom (5 to 13 May) and postbloom (12 to 16 July) at a rate of $1 \mathrm{~kg}$ a.i. per ha. In 1994 and 1995, rotted fruit ( $n=14$ to 60 in 1994 and 25 in 1995) were collected from each plot and the fungi isolated.

Isolation and identification of fungi. Cranberry fruit were surface-sterilized in $0.5 \% \mathrm{NaOCl}$ with $0.1 \%$ Tween 20 for $5 \mathrm{~min}$ and then cut in half transversely. Fruit was placed with the cut surface down on nonclarified V8 agar (200 ml of V8 juice, $3 \mathrm{~g}$ of $\mathrm{CaCO}_{3}$, $15 \mathrm{~g}$ of agar, and $800 \mathrm{ml}$ of distilled $\mathrm{H}_{2} \mathrm{O}$ ) in 90 -mm-diameter petri plates. Plates were incubated at room temperature $\left(20\right.$ to $\left.25^{\circ} \mathrm{C}\right)$ for 3 to 4 weeks under indirect fluorescent light. Fungi were initially identified directly from the isolation plates by using morphological characteristics of the spores and spore-producing structures. A total of 13 species were commonly isolated from rotted fruit, many of which could be identified by macroscopic cultural characteristics. Several additional species were rarely isolated, some of which were difficult to identify because they did not readily sporulate.

Data analysis. The frequency of each of the most common fungal species isolated from infected fruit across all sampling points was computed and plotted. These values represent an approximation of the average frequency for each of the fungal species. For seven of the most common fungal species, the frequency distributions were plotted. Comparisons of the fungal profiles among cultivars or between healthy and sound fruit were made using the Bray-Curtis distance value (11): $d_{i j}=\Sigma_{k}\left|x_{k i}-x_{k j}\right| / \Sigma_{k}\left(x_{k i}+x_{k j}\right)$, in which the distance $(d)$ between the two classes $(i$ and $j$ ) is determined using the number of times $(x)$ each fungal species $(k)$ was isolated. The result provides a numerical value between 0 and 1 in which smaller values indicate greater similarity between two samples. This distance metric was selected because it allowed comparisons based on frequency of isolation rather than simply presence or absence of each species (11). In cases in which two classes are compared (i.e., healthy versus rotted or 'Early Black' versus 'Stevens'), a single Bray-Curtis distance value was calculated for each year. However, when 10 cultivars were compared, a triangular distance matrix was obtained. In that case, an average distance value and standard deviation were calculated from the distance matrix for each year. To determine if two distance matrices were correlated, a Mantel's test for matrix correspondence was conducted (11). Bray-Curtis values and Mantel tests were computed using NTSYS-pc (version 1.8; Applied Biostatistics, Setauket, NY). All other calculations were performed using Microsoft Excel 97 (Microsoft Corp., Redmond, WA).

\section{RESULTS}

Survey for cranberry fruit rot fungi. The frequency of each fungal species isolated from rotted cranberry fruit was determined

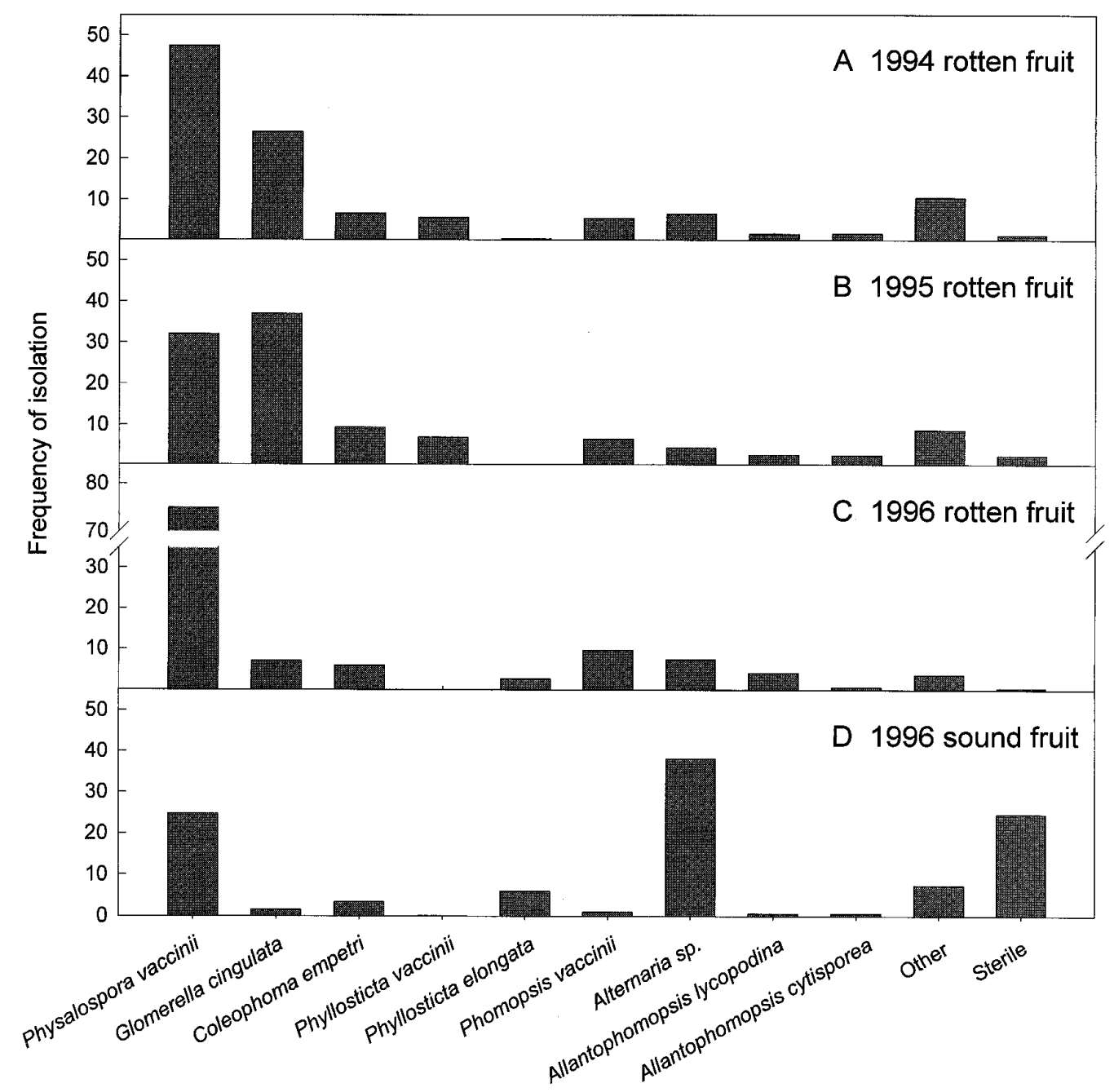

Fig. 1. Frequency of isolation of fungi from cranberry fruit. Data based on A, 3,600 rotted fruit from 36 beds in 1994 ; B, 4,000 rotted fruit from 40 beds in 1995; and C, 1,100 rotted and D, 1,100 sound fruit from 11 beds in 1996. "Sterile" indicates fruit from which no fungi were isolated. 
for all of the sites in each year. Physalospora vaccinii (Shear) Arx \& E. Müller and G. cingulata were the most consistently isolated fungi from rotted cranberry fruit in 1994 and 1995 (Fig. 1). In 1996, G. cingulata and Phyllosticta vaccinii Earle were isolated less frequently than in previous years (Fig. 1). Coleophoma empetri (Rostr.) Petr., Phomopsis vaccinii Shear in Shear, N. Stevens, \& H. Bain, and Alternaria spp. were isolated from rotted cranberry fruit at moderate levels in all 3 years (Fig. 1). Other known fruit-rot pathogens isolated less frequently from rotted cranberry fruit included Allantophomopsis lycopodina (Hohn.) Carris, Allantophomopsis cytisporea (Fr.:Fr.) Petr., and Phyllosticta elongata G.J. Weidemann (Fig. 1). In cases in which no fungi were isolated, the rotted fruit were designated as sterile and may have been affected by physiological breakdown or sunscald. Additional fungi were isolated from an average of $10.5,8.8$, and $8.1 \%$ of cranberry fruit sampled in 1994, 1995, and 1996, respectively. These fungi included Colletotrichum acutatum J.H. Simmonds, a Botrytis sp., Pestalotia vaccinii (Shear) Guba, two Penicillium spp., an Aureobasidium sp., a Trichoderma sp., a Cladosporium sp., a Sphaeropsis sp., a Curvularia sp., an Epicoccum sp., and a nonsporulating fungus. Species that were rarely isolated in the current study included Rhabdospora oxycocci Shear, a Septoria sp., and Pseudotracylla falcata Carris. Unidentified fungi were isolated from 10.6, 9.3, and $4.6 \%$ of sampled fruit in 1994, 1995, and 1996, respectively. In 1995, when fungi were isolated from fruit in unmanaged, abandoned cranberry beds, the frequencies of other fungi (22.2\% of rotted fruit) and unidentified fungi $(15.9 \%)$ were generally higher. One fungus, Fusicoccum putrefaciens Shear (teleomorph: Godronia cassandrae Peck), was recovered in less than $1 \%$ of the total isolations.

In 1994, Physalospora vaccinii was found in all 36 beds and $G$. cingulata was found in 33 of the 36 cranberry beds sampled (Fig. 2A). In 1995, Physalospora vaccinii was found in all 40 beds

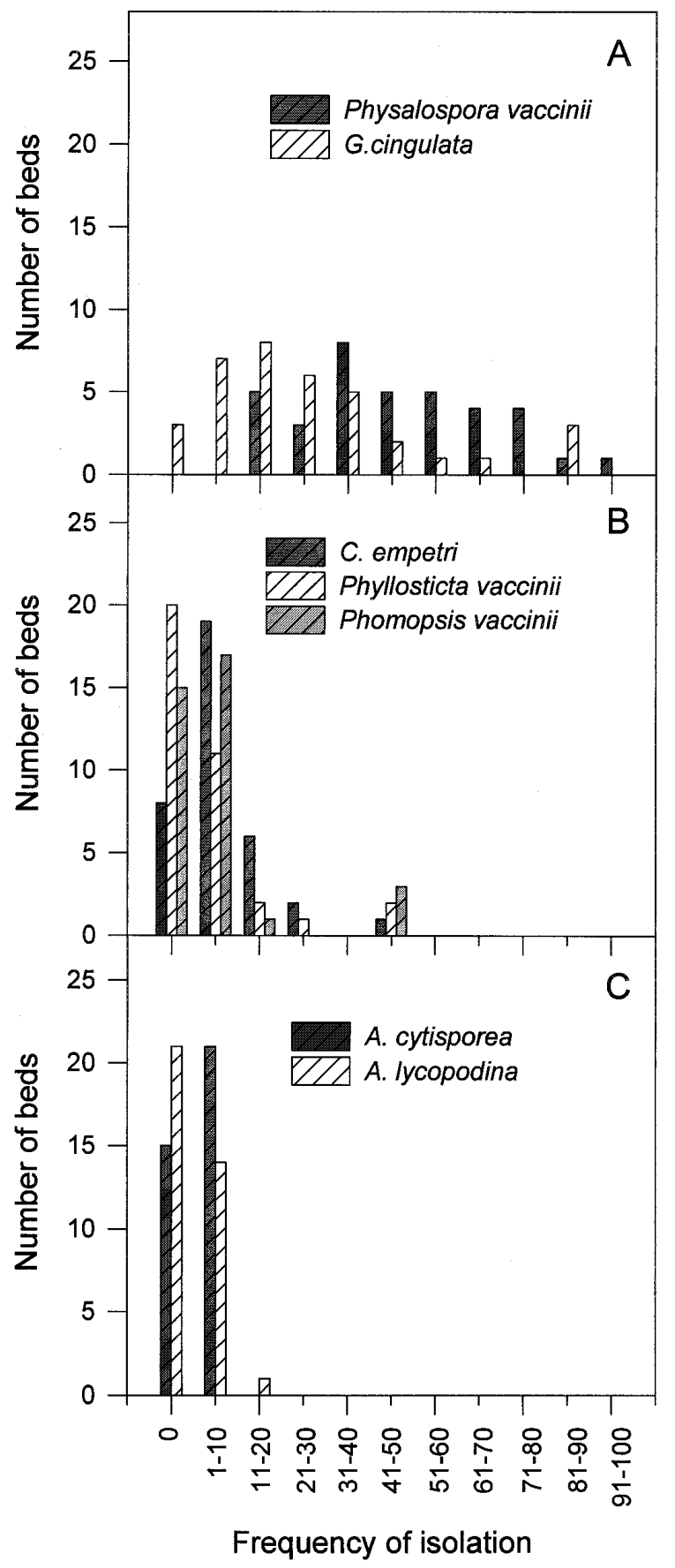

Fig. 2. Frequency of isolation of seven cranberry fruit-rotting fungi isolated from 36 commercial cranberry beds in 1994.

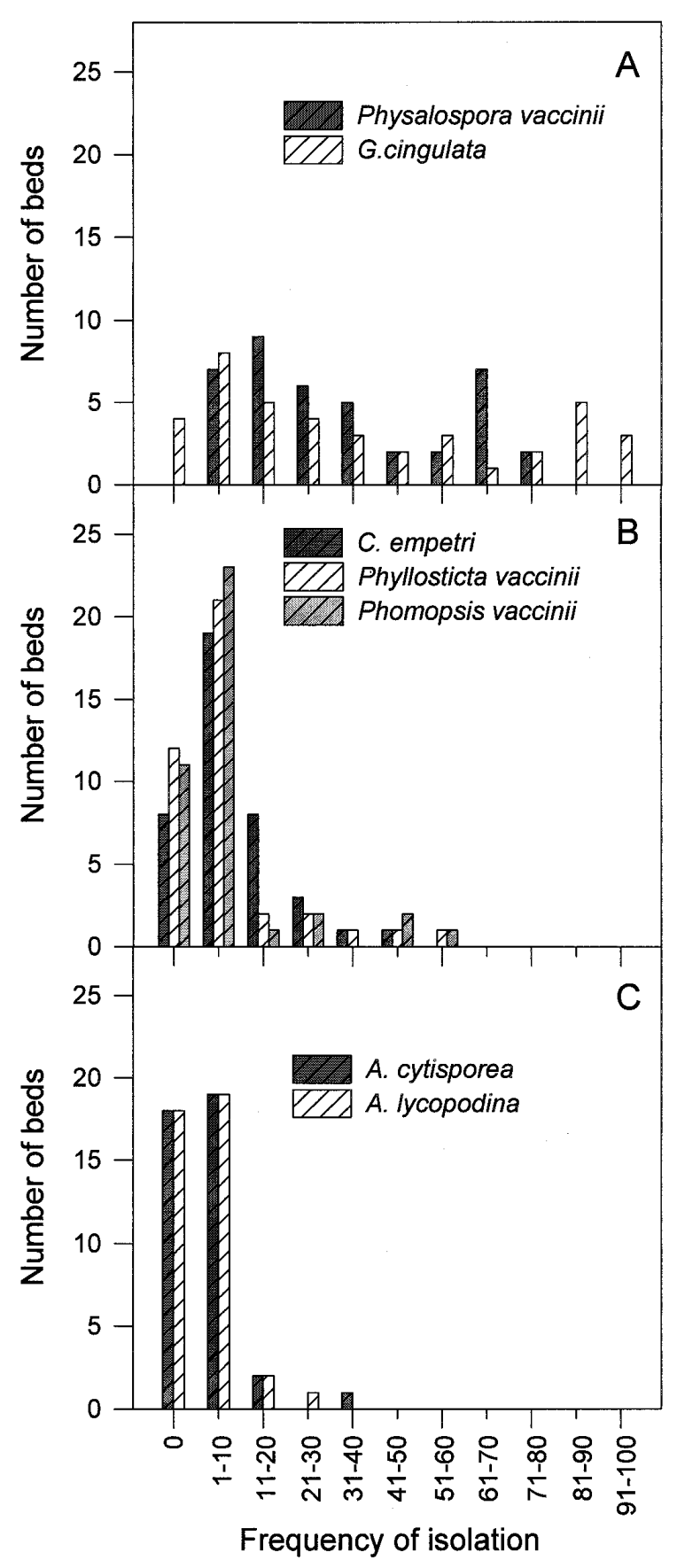

Fig. 3. Frequency of isolation of seven cranberry fruit-rotting fungi isolated from 40 commercial cranberry beds in 1995 . 
sampled and G. cingulata was found in 36 of 40 beds sampled (Fig. 3A). Phomopsis vaccinii was isolated from 0 to $5 \%$ of rotted berries from most beds sampled; however, this fungus was isolated from rotted fruit collected from five beds at frequencies ranging from 17 to 53\% (Figs. 2B and 3B). These five beds were clustered in two locations (i.e., farms). Similarly, Phyllosticta vaccinii and Coleophoma empetri were abundant on a small number of beds (Figs. 2B and 3B) that tended to be clustered in one or a few locations. The black-rotting fungi, A. cytisporea and A. lycopodina, were widespread but at uniformly low frequencies (Figs. 2C and 3C).

Comparison of fungi in healthy and rotted fruit. The profiles of fungi inhabiting healthy and rotted fruit were different (Tables 2, 3, and 4). In commercial, managed beds that received regular fungicide applications, the sound fruit that were designated as sterile ranged in frequency from 0 to $57 \%$ (Tables 3 and 4, Fig. 1D). However, in native or unmanaged beds, sound fruit were nearly $100 \%$ infected by various fungal species (Table 2). In general, Phyllosticta elongata and an Alternaria sp. were more common in healthy fruit, whereas Physalospora vaccinii, G. cingulata, and Coleophoma empetri were isolated more frequently from rotted fruit. Comparisons of the fungal profiles between these two classes of fruit over a 2-year period yielded high (>0.5) Bray-Curtis distance values (Fig. 4A).

Isolation of fungi from cranberry fruit in native or abandoned beds. Healthy and rotted cranberry fruit collected from one abandoned, unmanaged bed in 1994 and from four abandoned, unmanaged beds as well as one native stand in 1995 yielded a simi- lar array of fungi as was found in the commercial, managed beds (Table 2). Physalospora vaccinii was isolated most consistently from rotted fruit (Table 2). Phyllosticta elongata was isolated most consistently from healthy fruit, while Physalospora vaccinii was found at moderately high levels at three of the five locations (Table 2). Phomopsis vaccinii and Coleophoma empetri were present at one location (Friendship) in 1994, but were not detected in 1995 at that location. G. cingulata was rarely isolated $(3.0 \%$ or less of the fruit) from either rotted or healthy fruit in these beds (Table 2).

Comparison of fungal profiles among cultivars. At 11 sites, rotted cranberry fruit from paired beds representing two cranberry cultivars (Early Black and Stevens) yielded similar fungal profiles (Table 5). The frequencies of the fungal species (Table 5) were not significantly different $(P=0.48)$ when subjected to an analysis of variance, and use of the Bray-Curtis distance value indicated that only small differences exist in the fungal profiles $(\sim 0.1)$ and values calculated for 1994 and 1995 were similar (Fig. 4B). For the 10 cultivars in the experimental bed, 10 fungal species were regularly isolated (Table 6). In 1994 and 1995, very similar profiles emerged, with the exception that in 1994 Phyllosticta vaccinii and A. cytisporea were present at higher levels, while in 1995 Coleophoma empetri was isolated more frequently than in 1994 (Table 6). Intermediate levels of the Bray-Curtis distance measure were obtained for both years (Fig. 4C), indicating that there were no strong differences in frequency between fungal profiles from the different varieties. No evidence for correlation was found between the

TABLE 2. Percentage of cranberry fruit from unmanaged cranberry beds and native stands in New Jersey ${ }^{a}$ yielding various species of fungi

\begin{tabular}{|c|c|c|c|c|c|c|c|c|c|}
\hline & \multirow{3}{*}{$\begin{array}{c}1994 \\
\text { Site } 4 \\
\text { Rotted } \\
(n=40)\end{array}$} & \multicolumn{8}{|c|}{1995} \\
\hline & & \multirow{2}{*}{$\begin{array}{c}\text { Site } 1 \\
\text { Rotted } \\
(n=100)\end{array}$} & \multicolumn{2}{|c|}{ Site 2} & \multicolumn{2}{|c|}{ Site 3} & \multicolumn{2}{|c|}{ Site 4} & \multirow{2}{*}{$\begin{array}{c}\text { Site } 5 \\
\text { Sound } \\
(n=93)\end{array}$} \\
\hline & & & $\begin{array}{c}\text { Rotted } \\
(n=100)\end{array}$ & $\begin{array}{c}\text { Sound } \\
(n=100)\end{array}$ & $\begin{array}{c}\text { Rotted } \\
(n=64)\end{array}$ & $\begin{array}{c}\text { Sound } \\
(n=50)\end{array}$ & $\begin{array}{c}\text { Rotted } \\
(n=23)\end{array}$ & $\begin{array}{l}\text { Sound } \\
(n=8)\end{array}$ & \\
\hline Coleophoma empetri & 20 & 2 & 2 & 0 & 2 & 2 & 0 & 0 & 1 \\
\hline Phyllosticta vaccinii & 3 & 20 & 24 & 2 & 0 & 0 & 26 & 63 & 0 \\
\hline Phyllosticta elongata & 3 & 1 & 5 & 94 & 0 & 68 & 4 & 0 & 28 \\
\hline Allantophomopsis cytisporea & 0 & 0 & 0 & 0 & 0 & 0 & 0 & 0 & 0 \\
\hline No fungi & 0 & 0 & 0 & 1 & 0 & 0 & 0 & 0 & 0 \\
\hline Other $^{\mathrm{b}}$ & 35 & 52 & 9 & 14 & 11 & 12 & 39 & 50 & 17 \\
\hline Unknown & 18 & 23 & 10 & 16 & 25 & 56 & 22 & 13 & 39 \\
\hline
\end{tabular}

a Site 1 = Middle Run, Burlington County; 2 = Otis Bog Road, Ocean County; 3 = Island Beach, Ocean County; 4 = Friendship, Burlington County; and 5 = Eagleswood Township, Ocean County.

${ }^{\mathrm{b}}$ Other species are listed in the text.

TABLE 3. Percentage of healthy and rotted cranberry fruit from eight commercial cranberry beds in New Jersey in 1995 from which fungi were isolated

\begin{tabular}{|c|c|c|c|c|c|c|c|c|c|c|c|}
\hline Bed & Status & $n$ & $\begin{array}{c}\text { Physalospora } \\
\text { vaccinii }\end{array}$ & $\begin{array}{c}\text { Glomerella } \\
\text { cingulata }\end{array}$ & $\begin{array}{l}\text { Coleophoma } \\
\text { empetri }\end{array}$ & $\begin{array}{l}\text { Phyllosticta } \\
\text { elongata }\end{array}$ & $\begin{array}{l}\text { Alternaria } \\
\text { spp. }\end{array}$ & $\begin{array}{l}\text { Allantophomopsis } \\
\text { lycopodina }\end{array}$ & $\begin{array}{c}\text { Allantophomopsis } \\
\text { cytisporea }\end{array}$ & Sterile $^{\mathrm{a}}$ & Other $^{\mathrm{b}}$ \\
\hline 41 & Sound & 30 & 43 & 0 & 0 & 17 & 17 & 0 & 0 & 13 & 10 \\
\hline 42 & Sound & 30 & 30 & 0 & 0 & 13 & 17 & 0 & 3 & 10 & 10 \\
\hline 44 & Sound & 30 & 0 & 0 & 0 & 3 & 23 & 0 & 0 & 53 & 17 \\
\hline 36 & Sound & 30 & 10 & 0 & 0 & 10 & 10 & 0 & 0 & 47 & 0 \\
\hline 37 & Sound & 30 & 3 & 0 & 0 & 0 & 7 & 0 & 0 & 43 & 13 \\
\hline 45 & Sound & 30 & 10 & 0 & 3 & 37 & 20 & 0 & 3 & 10 & 17 \\
\hline 41 & Rotted & 30 & 17 & 40 & 63 & 0 & 0 & 0 & 0 & 3 & 0 \\
\hline 42 & Rotted & 20 & 0 & 25 & 70 & 0 & 0 & 0 & 0 & 0 & 0 \\
\hline 72 & Rotted & 17 & 0 & 47 & 6 & 0 & 6 & 0 & 18 & 12 & 6 \\
\hline 44 & Rotted & 11 & 18 & 55 & 0 & 0 & 9 & 0 & 0 & 18 & 0 \\
\hline 36 & Rotted & 24 & 4 & 79 & 8 & 0 & 0 & 0 & 0 & 0 & 8 \\
\hline 37 & Rotted & 18 & 11 & 6 & 0 & 0 & 6 & 6 & 17 & 6 & 6 \\
\hline 45 & Rotted & 29 & 0 & 35 & 66 & 0 & 7 & 10 & 7 & 0 & 0 \\
\hline
\end{tabular}

${ }^{\text {a }}$ Sterile fruit, no fungi isolated.

b Other fungi are listed in the text.

c The frequencies of each isolation column were tested for differences between sound and rotted fruit using analysis of variance; ns = not significant. 
matrices for 1994 and $1995(r=-0.0179)$. The value $r$ is equivalent to the Mantel $Z$ statistic. The null hypothesis that a random $Z$ (generated by randomizing one of the distance matrices) was less than the observed $Z$ could not be rejected (Mantel $t=0.12, P=$ $0.45)$, indicating that the matrices were not correlated.

\section{DISCUSSION}

Cranberry fruit rot is a disease complex involving as many as 32 species of fungi $(12,16)$. Pathogenicity of some of the suspected fruit-rot pathogens has been established following Koch's postulates. These include Physalospora vaccinii (2), Phyllosticta elongata (23), G. cingulata (C. M. Stiles and P. V. Oudemans, unpublished data), and Phyllosticta vaccinii (23). In a disease complex such as cranberry fruit rot, each fungal species may occur in varying frequencies in a given location or change in frequency during the growing season (10). Thus, the contribution of each pathogen species to actual crop loss is very difficult to establish. Field rot is the primary concern in cranberry production in New Jersey, and symptom expression is greatest at the time of harvest. In this study, over 9,000 rotted fruit and over 1,600 sound fruit were sampled from the field just prior to harvest during the period from 1994 to 1996.

In general, in commercial cranberry beds in New Jersey, Physalospora vaccinii and $G$. cingulata were the two most common and widely distributed fungi isolated from rotted, mature cranberry fruit in the first 2 years of this survey. In the third year, the frequency of $G$. cingulata declined markedly. Certain other fungal species were locally important to specific sites within the study area. Phomopsis

TABLE 4. Percentages of berries from which fungi were isolated in $1996^{\mathrm{a}}$

\begin{tabular}{|c|c|c|c|c|c|c|c|c|c|c|c|}
\hline Bed & Status & $\begin{array}{c}\text { Physalospora } \\
\text { vaccinii }\end{array}$ & $\begin{array}{l}\text { Glomerella } \\
\text { cingulata }\end{array}$ & $\begin{array}{l}\text { Coleophoma } \\
\text { empetri }\end{array}$ & $\begin{array}{l}\text { Phyllosticta } \\
\text { elongata }\end{array}$ & $\begin{array}{l}\text { Phomopsis } \\
\text { vaccinii }\end{array}$ & $\begin{array}{l}\text { Alternaria } \\
\text { spp. }\end{array}$ & $\begin{array}{c}\text { Allantophomopsis } \\
\text { lycopodina }\end{array}$ & $\begin{array}{c}\text { Allantophomopsis } \\
\text { cytisporea }\end{array}$ & Sterile $^{b}$ & Other ${ }^{c}$ \\
\hline 21 & Sound & 17 & 0 & 0 & 6 & 2 & 31 & 0 & 0 & 29 & 11 \\
\hline 22 & Sound & 6 & 0 & 0 & 1 & 4 & 72 & 0 & 2 & 12 & 5 \\
\hline 24 & Sound & 3 & 1 & 13 & 23 & 4 & 49 & 2 & 0 & 6 & 8 \\
\hline 32 & Sound & 37 & 0 & 0 & 3 & 0 & 15 & 0 & 0 & 23 & 15 \\
\hline 33 & Sound & 23 & 0 & 0 & 1 & 0 & 25 & 0 & 0 & 39 & 6 \\
\hline 34 & Sound & 18 & 0 & 3 & 1 & 0 & 34 & 1 & 4 & 22 & 16 \\
\hline 35 & Sound & 26 & 1 & 2 & 1 & 0 & 36 & 2 & 0 & 19 & 5 \\
\hline 36 & Sound & 17 & 0 & 14 & 0 & 0 & 24 & 0 & 0 & 47 & 3 \\
\hline 37 & Sound & 12 & 6 & 2 & 3 & 0 & 36 & 0 & 0 & 18 & 12 \\
\hline 41 & Sound & 37 & 1 & 0 & 14 & 0 & 37 & 1 & 0 & 13 & 1 \\
\hline 42 & Sound & 51 & 0 & 0 & 7 & 0 & 23 & 0 & 0 & 20 & 1 \\
\hline 21 & Rotted & 29 & 1 & 1 & 4 & 49 & 11 & 0 & 0 & 0 & 5 \\
\hline 22 & Rotted & 40 & 0 & 3 & 4 & 28 & 16 & 4 & 0 & 0 & 5 \\
\hline 24 & Rotted & 40 & 14 & 23 & 1 & 12 & 3 & 27 & 2 & 0 & 9 \\
\hline 32 & Rotted & 85 & 1 & 0 & 1 & 1 & 2 & 0 & 0 & 0 & 4 \\
\hline 33 & Rotted & 91 & 0 & 3 & 5 & 2 & 4 & 1 & 0 & 0 & 4 \\
\hline 34 & Rotted & 77 & 4 & 0 & 1 & 0 & 14 & 0 & 0 & 1 & 0 \\
\hline 35 & Rotted & 85 & 1 & 1 & 1 & 0 & 2 & 0 & 1 & 0 & 2 \\
\hline 36 & Rotted & 63 & 0 & 8 & 2 & 0 & 17 & 2 & 1 & 4 & 4 \\
\hline 37 & Rotted & 70 & 24 & 8 & 5 & 3 & 3 & 4 & 2 & 0 & 5 \\
\hline 41 & Rotted & 73 & 7 & 12 & 3 & 0 & 1 & 3 & 0 & 0 & 3 \\
\hline 42 & Rotted & 96 & 0 & 1 & 0 & 2 & 2 & 1 & 1 & 0 & 0 \\
\hline \multicolumn{2}{|c|}{ Significance $^{\mathrm{d}}$} & $<0.001$ & ns & ns & ns & ns & $<0.001$ & ns & ns & $<0.001$ & 0.04 \\
\hline
\end{tabular}

a Rotted and sound berries (100 from each class) were collected just before harvest (13 to 29 September) from 11 commercial cranberry beds in New Jersey.

b Sterile fruit, no fungi isolated.

c Other fungi are listed in the text.

$\mathrm{d}$ The frequencies of each isolation column were tested for differences between sound versus rotted fruit using analysis of variance; ns = not significant.

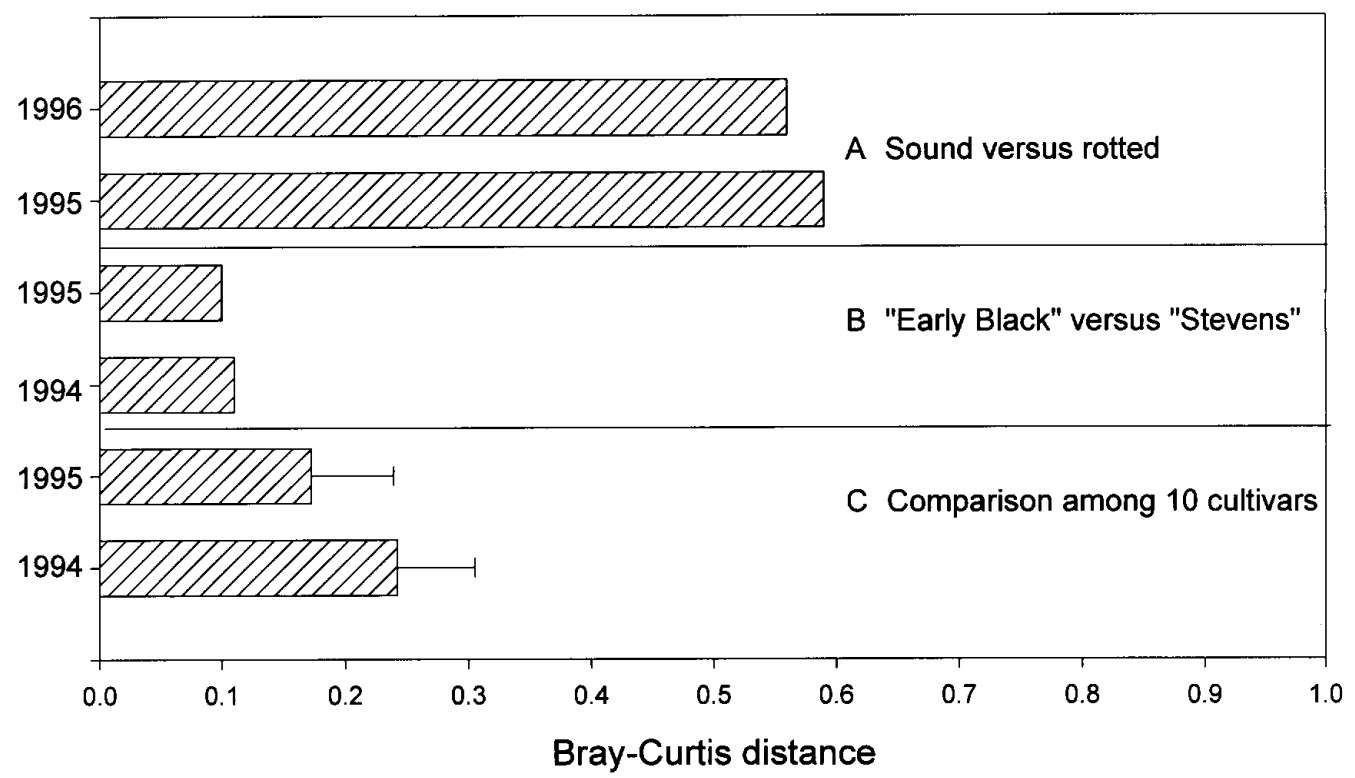

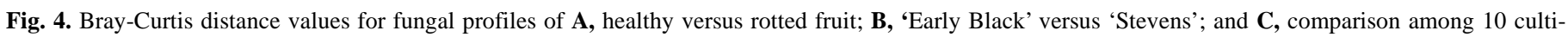
vars. Bray-Curtis values can range from 0 to 1 , in which 0 represents identical frequencies and species profile. 
vaccinii was found in much higher frequencies from rotted fruit in several cranberry beds in two areas of Burlington County. Phomopsis vaccinii is also believed to be the main causal agent of upright dieback, a disease that is initiated early in the growing season (8). Symptoms of upright dieback appeared to be correlated with occurrence of the fruit rot stage (P. V. Oudemans, personal observation). In addition, Coleophoma empetri and Phyllosticta vaccinii were present at greater frequency at a small number of sites.

During the period from 1926 to 1929, Shear et al. (16) reported Guignardia vaccinii as the most common fungus isolated from stored, rotted cranberries in New Jersey. It was later shown that Guignardia vaccinii encompassed two species now recognized as Phyllosticta vaccinii and Phyllosticta elongata (24). Phyllosticta vaccinii is the causal agent of early fruit rot, as well as a leaf drop and blossom blast of cranberry. In contrast, Phyllosticta elongata is associated with latent infections of cranberry leaves and fruit, but also causes a berry speckle and a postharvest fruit rot (23). The apparent decline in frequency of Phyllosticta spp. over the past 70 years may be the result of several factors. It was confirmed in this study that Phyllosticta elongata occurred more frequently in healthy (nonrotted) fruit, as reported previously (23). Thus, in the results reported by Shear et. al. (16), it is possible that Phyllosticta elongata was more

TABLE 5. Percentage of fungal species isolated from rotted fruit of two cultivars over a 2-year period ${ }^{\mathrm{a}}$

\begin{tabular}{|c|c|c|c|c|}
\hline \multirow[b]{2}{*}{ Fungal species } & \multicolumn{2}{|c|}{1994} & \multicolumn{2}{|c|}{1995} \\
\hline & 'Early Black' & 'Stevens' & 'Early Black' & 'Stevens' \\
\hline Physalospora vaccinii & 47.10 & 49.74 & 29.55 & 33.31 \\
\hline Glomerella cingulata & 21.80 & 20.02 & 39.55 & 40.67 \\
\hline Phomopsis vaccinii & 10.68 & 5.03 & 14.27 & 6.00 \\
\hline Alternaria spp. & 8.90 & 5.66 & 4.55 & 3.09 \\
\hline Penicillium spp. & 6.80 & 10.75 & 3.36 & 4.64 \\
\hline Coleophoma empetri & 6.44 & 5.63 & 10.73 & 12.01 \\
\hline Phyllosticta vaccinii & 3.55 & 4.82 & 7.09 & 3.28 \\
\hline Bacteria/yeast & 3.10 & 3.67 & 1.27 & 1.37 \\
\hline Allantophomopsis cytisporea & 2.78 & 1.32 & 1.64 & 1.64 \\
\hline Allantophomopsis lycopodina & 1.31 & 1.98 & 1.45 & 1.55 \\
\hline Pestalotia vaccinii & 0.45 & 1.52 & 0.91 & 2.00 \\
\hline Colletotrichum acutatum & 0.36 & 1.29 & 0.55 & 0.82 \\
\hline Phyllosticta elongata & 0.32 & 0.18 & 0.00 & 0.00 \\
\hline Botrytis sp. & 0.30 & 0.39 & 0.64 & 0.82 \\
\hline Epicoccum sp. & 0.00 & 0.00 & 0.73 & 0.27 \\
\hline
\end{tabular}

${ }^{\text {a }}$ Fruit $(n=100)$ were collected from 11 cranberry beds of each cranberry cultivar. The percentages of each fungal species were tested using analysis of variance and no significant differences were found. prevalent in the stored, rotted fruit, but was a relatively minor component in field-rotted fruit. In this study, Phyllosticta vaccinii was isolated more frequently from field-rotted as opposed to sound fruit, and the highest frequencies of this fungus were found in unmanaged, abandoned, or unsprayed commercial beds. The estimates on the frequency of the fungus reported here are probably low because early-rotted fruit would not have been sampled at harvest.

Physalospora vaccinii and $G$. cingulata were the second and third most commonly isolated fungi in New Jersey during 1926 to 1929 (16). G. cingulata was the most common fungus isolated from recently stored, rotted cranberries in Massachusetts during 1926 to 1929 (16) and also 1956 to 1957 (27). More recently, results indicate that the frequency of $G$. cingulata has decreased in the cranberry-growing regions of Massachusetts, while the frequencies of Coleophoma empetri and Phyllosticta vaccinii have increased (F. L. Caruso, personal communication). In this study, Physalospora vaccinii, Phomopsis vaccinii, and Coleophoma empetri were more consistently present at specific locations, while $G$. cingulata varied greatly in frequency from 1994 to 1996. This is consistent with studies that report large fluctuations in the frequency of $G$. cingulata from one season to the next $(20,27)$

Storage-rot fungi are those species that reduce fruit quality during storage. In this study, major differences were observed in the fungal profiles from sound versus rotted fruit. On average, approximately $75 \%$ of the sound fruit yielded at least one fungal species. Phyllosticta elongata and an Alternaria sp. were the most common fungi isolated from sound fruit in this study. Surprisingly, Fusicoccum putrefaciens was rarely found in the current study. Shear (16) considered this the most important of the fruitrotting fungi in North America and isolated it from about $6 \%$ of stored, rotted berries prior to 1 November in New Jersey in 1926 to 1929. Although this fungus causes storage rot, it has been shown that infections occur in the field prior to harvest and remain latent. The frequency of Fusicoccum putrefaciens may have been underestimated because isolations were made at room temperature (20 to $25^{\circ} \mathrm{C}$ ), which is above the optimum growth temperature (15 to $20^{\circ} \mathrm{C}$ ) for this species. Black-rotting fungi including A. cytisporea and A. lycopodina were isolated at low frequencies, but from a large number of sample sites. This is consistent with other studies in which the majority of infections by these fungi occur during the water-harvesting process and very low infection levels occur prior to flooding of the beds $(4,14,21)$. Thus, the black-rotting fungi are widespread in New Jersey and represent a significant threat to water-harvested fruit destined for the fresh market.

TABLE 6. Percentage of fungal species isolated from rotted fruit of cranberry cultivars in experimental bed ${ }^{a}$

\begin{tabular}{|c|c|c|c|c|c|c|c|c|c|c|c|}
\hline \multirow[b]{2}{*}{ Species } & \multirow[b]{2}{*}{ Year } & \multicolumn{10}{|c|}{ Cultivar } \\
\hline & & \#35 & Ben Lear & Cropper & Crowley & Early Black & Franklin & Howes & Pilgrim & Stevens & Wilcox \\
\hline \multirow[t]{2}{*}{ Allantophomopsis lycopodina } & 1994 & 1.3 & 10.0 & 0.0 & 0.4 & 2.8 & 3.8 & 0.4 & 0.0 & 2.7 & 1.6 \\
\hline & 1995 & 2.0 & 0.0 & 5.0 & 3.0 & 1.0 & 2.0 & 2.1 & 0.0 & 4.0 & 1.0 \\
\hline \multirow[t]{2}{*}{ Allantophomopsis cytisporea } & 1994 & 3.8 & 3.6 & 2.5 & 10.0 & 7.8 & 8.1 & 4.3 & 6.7 & 7.5 & 2.3 \\
\hline & 1995 & 2.1 & 2.0 & 0.0 & 3.0 & 0.0 & 1.0 & 3.3 & 0.0 & 1.0 & 3.0 \\
\hline \multirow[t]{2}{*}{ Coleophoma empetri } & 1994 & 0.0 & 0.8 & 0.0 & 0.0 & 0.0 & 0.4 & 0.4 & 0.0 & 0.0 & 0.0 \\
\hline & 1995 & 22.1 & 13.0 & 14.0 & 32.0 & 37.0 & 26.0 & 17.1 & 36.0 & 26.0 & 17.0 \\
\hline \multirow[t]{2}{*}{ Physalospora vaccinii } & 1994 & 33.3 & 23.5 & 31.8 & 36.7 & 19.5 & 30.1 & 32.3 & 36.3 & 23.8 & 30.4 \\
\hline & 1995 & 58.7 & 73.8 & 80.0 & 64.0 & 55.0 & 53.0 & 70.0 & 48.0 & 58.0 & 67.0 \\
\hline \multirow[t]{2}{*}{ Phyllosticta vaccinii } & 1994 & 6.7 & 2.5 & 11.4 & 8.3 & 4.8 & 1.3 & 12.3 & 7.2 & 8.4 & 9.2 \\
\hline & 1995 & 2.0 & 0.0 & 5.0 & 3.0 & 3.0 & 3.0 & 9.2 & 3.0 & 2.0 & 6.0 \\
\hline \multirow[t]{2}{*}{ Phyllosticta elongata } & 1994 & 2.3 & 0.4 & 0.4 & 0.0 & 1.3 & 1.7 & 0.0 & 0.0 & 1.4 & 2.7 \\
\hline & 1995 & 0.0 & 0.0 & 0.0 & 0.0 & 1.0 & 1.0 & 0.0 & 0.0 & 0.0 & 0.0 \\
\hline \multirow[t]{2}{*}{ Phomopsis vaccinii } & 1994 & 2.0 & 0.0 & 0.0 & 0.0 & 1.7 & 0.4 & 0.0 & 0.0 & 0.0 & 0.0 \\
\hline & 1995 & 4.0 & 0.0 & 2.0 & 1.0 & 2.0 & 4.0 & 0.0 & 1.0 & 4.0 & 0.0 \\
\hline \multirow[t]{2}{*}{ Colletotrichum acutatum } & 1994 & 0.0 & 0.8 & 0.9 & 0.4 & 0.4 & 0.0 & 1.3 & 0.0 & 1.7 & 0.0 \\
\hline & 1995 & 0.0 & 0.0 & 3.0 & 0.0 & 2.0 & 0.0 & 0.0 & 0.0 & 0.0 & 0.0 \\
\hline \multirow[t]{2}{*}{ Glomerella cingulata } & 1994 & 0.5 & 3.8 & 4.8 & 9.6 & 6.8 & 8.4 & 0.8 & 5.4 & 11.0 & 3.5 \\
\hline & 1995 & 7.0 & 8.0 & 16.0 & 12.0 & 11.0 & 16.0 & 8.2 & 18.0 & 10.0 & 13.0 \\
\hline \multirow[t]{2}{*}{ Pestalotia vaccinii } & 1994 & 5.5 & 6.9 & 12.9 & 5.9 & 6.3 & 6.3 & 6.2 & 8.8 & 3.8 & 5.0 \\
\hline & 1995 & 1.0 & 1.0 & 7.0 & 1.0 & 1.0 & 1.0 & 2.1 & 3.0 & 1.0 & 2.0 \\
\hline
\end{tabular}

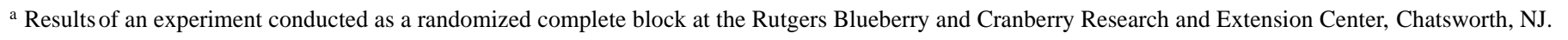


Berries exhibiting rot symptoms that yielded no fungi were infrequent in the current study (1.4\% in 1994 and $2.6 \%$ in 1995, compared with $\sim 17 \%$ in 1926 to 1929) (16). In a few beds, the frequency of rotted berries that yielded no fungi upon isolation was higher $(>50 \%)$, and it is likely that berries exhibiting symptoms of sunscald were sampled more frequently than berries that were rotted due to fungal infection. In general, when fungi were isolated from berries in unmanaged, abandoned beds, the frequency of the "other fungi" and "unknown" classes were higher. The greater fungal diversity in those beds may be due, in part, to the lack of fungicide use. However, those sampled areas were always mixed stands where other plant species, especially grasses and sedges, also were abundant. The higher fungal diversity may be a result of higher plant diversity or an improved environment for fungal growth because of greater plant density. In sound fruit, the proportion of berries from which no fungi were isolated was higher than among rotted fruit, except in unmanaged beds where the majority of fruit were infected. The fungicide chlorothalonil is commonly used in cranberry culture and is known to have an extended residual period. Thus, the protective effects of the fungicide program may be responsible for a greater level of apparently sterile fruit. The majority of fungi isolated from sound fruit were weak pathogens, storage pathogens, or saprophytes.

Comparisons among beds with over $10 \%$ fruit rot did not reveal the presence of a single fungal species responsible for the higher levels of rot (data not shown). In fact, each case was unique. The major fruitrotting organisms, depending on the location, appear to be Physalospora vaccinii, Coleophoma empetri, G. cingulata, Phomopsis vaccinii, and Phyllosticta vaccinii. It did not appear, from the data obtained for this study, that increases or high levels of disease could be attributed to a single fungal species. The cause of higher levels of disease is likely to rest on grower practices or environmental conditions that could favor fungal development or physiological breakdown of fruit.

The results of this survey show that cranberry fruit rot is a dynamic disease complex. Different fungal species predominate at different locations, and the frequencies can vary greatly over time. For example, Shear (15) reported Coleophoma empetri as being nonexistent in New Jersey during the 1920s. In this survey, Coleophoma empetri was abundant at a few locations. It is, therefore, evident that the abundance of different fruit-rotting species has changed significantly over the past 70 years. The practice of distributing vines for propagation probably has resulted in movement of different species of fruit-rotting fungi (12). Current controls for fruit rot include mainly broad-spectrum fungicides such as chlorothalonil, mancozeb, and ferbam, as well as the occasional use of fixed-copper sprays. Eventual replacement of these fungicides with newer, more selective ones could result in dramatic shifts in the species compositions. Therefore, as new fungicide registrations occur, it is likely that different management strategies will be required to prevent selection of specific pathogen groups.

With the exception of cranberry false blossom disease, relatively little research has been published on disease resistance in cranberry. Anecdotal evidence regarding differences in fruit-rot resistance among cultivars remains untested. In this study, two cultivars, Early Black and Stevens, both commonly grown in New Jersey, were compared for differences in fungal profiles. 'Early Black' was originally selected from native beds in Massachusetts, whereas 'Stevens' is a selection introduced from the United States Department of Agriculture (USDA) breeding program during the 1950s. Although these two cultivars differ in genetic background, very similar fungal profiles were obtained. If cranberry cultivars were differentially susceptible to the various fungal species, then differences in the fungal profiles should emerge. In no instance were any of the fungal species present on one cultivar but excluded completely from the other cultivar. These observations were supported when 10 cultivars were compared. If consistent differences in the frequencies of fungal species occurred on different cultivars, the results from the Mantel correlation test should have yielded a positive, significant correlation. This did not occur; therefore, the hypothesis can be made that fungal speciesspecific resistance for fruit rot does not exist among the 10 cranberry cultivars tested. Further research is necessary to define how resistance to cranberry fruit rot operates.

\section{ACKNOWLEDGMENTS}

This work was supported by grants from USDA-CSRS and Ocean Spray Cranberries, Inc. We thank D. Schiffhauer, L. Brescia, D. Kerlin, G. Crawford, and C. Constantelos for technical assistance.

\section{LITERATURE CITED}

1. Bain, H. F. 1926. Cranberry disease investigations on the Pacific coast. U.S. Dep. Agric. Bull. 1434.

2. Brown, K. J. 1982. Physalospora vaccinii and its effect on cranberries in Wisconsin. M.S. thesis. University of Wisconsin, Madison.

3. Carris, L. M. 1988. Chalara vaccinii sp. nov., a Vaccinium endophyte. Mycologia 80:875-879.

4. Carris, L. M. 1990. Cranberry black rot fungi: Allantophomopsis cytisporea and Allantophomopsis lycopodina. Can. J. Bot. 68:2283-2291.

5. Carris, L. M. 1994. Vaccinium fungi: Mycosysimbrium cirrhosum gen. et. sp. nov. Mycologia 86:131-133.

6. Caruso, F. L., and Ramsdell, D. C., eds. 1995. Compendium of Blueberry and Cranberry Diseases. The American Phytopathology Society, St. Paul, MN.

7. Eck, P. 1990. The American Cranberry. Rutgers University Press, New Brunswick, NJ.

8. Friend, R. J., and Boone, D. M. 1968. Diaporthe vaccinii associated with dieback of cranberry in Wisconsin. Plant Dis. Rep. 52:341-344.

9. Halsted, B. D. 1889. Some fungus diseases of the cranberry. N.J. Agric. Coll. Exp. Stn. Bull. 64.

10. Jeffers, S. N. 1991. Seasonal incidence of fungi in symptomless cranberry leaves and fruit treated with fungicides during bloom. Phytopathology 81:636-644.

11. Legendre, L., and Legendre, P. 1983. Numerical Ecology. Elsevier, New York.

12. Oudemans, P. V., Caruso, F. L., and Stretch, A. W. 1998. Cranberry fruit rot in the northeast: A complex disease. Plant Dis. 82:1176-1184.

13. Roper, T. R., and Vorsa, N. 1997. Cranberry: Botany and horticulture. Hortic. Rev. 21:215-249.

14. Schwarz, M. R., and Boone, D. M. 1985. Effect of wounding on the incidence of black rot of cranberry in Wisconsin. Plant Dis. 69:225-227.

15. Shear, C. L., and Bain, H. F. 1929. Life history and pathological aspects of Godronia cassandrae Peck (Fusicoccum putrefaciens Shear) on cranberry. Phytopathology 19:1017-1024.

16. Shear, C. L., Stevens, N. E., and Bain, H. F. 1931. Fungous diseases of the cultivated cranberry. U.S. Dep. Agric. Tech. Bull. 258.

17. Stevens, N. E. 1924. Notes on cranberry fruit rot in Massachusetts. Phytopathology 14:101-107.

18. Stevens, N. E., and Bain, H. F. 1927. Storage rots of cranberries in the 1926 crop. Phytopathology 17:649-655.

19. Stevens, N. E., and Bain, H. F. 1928. Storage rots of cranberry in the 1927 crop. Phytopathology 18:809-814.

20. Stevens, N. E., and Bain, H. F. 1929. Storage rots of cranberries in the 1928 crop. Phytopathology 19:1037-1039.

21. Stretch, A. W., and Ceponis, A. J. 1983. Influence of water immersion time and storage period on black rot development in cold-stored, waterharvested cranberries. Plant Dis. 67:21-23.

22. Uecker, F. A., and Caruso, F. L. 1988. Synchronoblastia crypta, a new coelomycetous pathogen of upright stems and fruits of cranberry. Mycologia 80:344-347.

23. Weideman, G. J., and Boone, D. M. 1982. Taxonomy of Phyllosticta vaccinii (Coelomycetes) and a new name for the true anamorph of Botryosphaeria vaccinii (Dothideales, Dothioraseae). Mycologia 74:59-65.

24. Weideman, G. J., and Boone, D. M. 1983. Incidence and pathogenicity of Phyllosticta vaccinii and Botryosphaeria vaccinii on cranberry. Plant Dis. 67:1090-1093.

25. White, J. J. 1870. Cranberry Culture. Orange Judd and Company, New York.

26. Wilcox, R. B. 1940. Cranberry fruit rots in New Jersey. N.J. Agric. Exp. Stn. Circ. 403:1-4.

27. Zuckerman, B. M. 1958. Relative importance of cranberry fruit rot fungi during the storage and harvest seasons in Massachusetts, 1956-1957. Plant Dis. Rep. 42:1214-1221. 